\title{
PHOSPHORYLASE ACTIVITY IN RAT LIVER AND SKELETAL MUSCLE AFTER CATECHOLAMINES*
}

\author{
K. R. HORNBROOK† and T. M. BRODY \\ Department of Pharmacology, University of Michigan, Ann Arbor, Mich., U.S.A.
}

(Received 17 May 1963; accepted 1 July 1963)

\begin{abstract}
The time course of liver phosphorylase activation after catecholamine administration and the relative abilities of several adrenergic blocking agents to block catecholamine-induced phosphorylase activation in liver and skeletal muscle was studied in intact anesthetized rats. Subcutaneously injected epinephrine and norepinephrine increased the liver phosphorylase activity, the peak effect occurring $10 \mathrm{~min}$ after injection. The liver phosphorylase levels were somewhat reduced $30 \mathrm{~min}$ after injection. Isoproterenol administration did not increase the level of rat liver phosphorylase. Blood glucose changes after catecholamine treatment did not mirror the changes in liver phosphorylase activity.

Complete blockade of the liver phosphorylase response to epinephrine was observed with the $\alpha$-adrenergic blocking agent ergotamine. Phenoxybenzamine and two $\beta$-adrenergic blocking agents, dichloroisoprolerenol and nethalide, gave partial blockade. These data indicate the difficulty in the classification of the liver metabolic receptor. The activation by epinephrine of skeletal muscle phosphorylase appears to be affected only by $\beta$-adrenergic blocking agents.
\end{abstract}

THE blood glucose elevation, liver phosphorylase activation, and glycogenolysis induced by the catecholamines have been extensively investigated. ${ }^{1,2}$ Although the phosphorylase response has been reported consistently for liver slices in vitro, an effect in vivo after catecholamine administration has been both confirmed and denied. ${ }^{3-5}$ The effect of adrenergic blocking agents on liver phosphorylase activation after catecholamine administration has not been clarified. ${ }^{6}$

Phosphorylase activation in skeletal muscle after catecholamine administration is well documented $;^{7,8}$ however, no data could be found demonstrating the nature of this response after adrenergic blocking agents.

The present investigation will be concerned with the time-response relationships of phosphorylase activation and blood glucose levels in rat liver after the administration of L-epinephrine, L-norepinephrine, and DL-isoproterenol and the susceptibility of epinephrine-induced activation of liver and skeletal muscle phosphorylase to adrenergic blockade.

\section{METHODS}

White female rats (180 to $200 \mathrm{~g}$, Holtzman strain) were used throughout the investigation. Rats were maintained on food at all times. Anesthesia was produced by the intraperitoneal injection of hexobarbital sodium (150 to $180 \mathrm{mg} / \mathrm{kg}$ ) $10 \mathrm{~min}$ before sacrifice or catecholamine infusion.

* Supported by a contract between The University of Michigan and the Office of Naval Research, NONR-1224-27.

+ Present address: Dept. of Pharmacology, Washington Univ., School of Medicine, St. Louis, Mo., U.S.A. 
Commercial solutions of L-epinephrine (Adrenalin, Parke-Davis and Co), or crystalline L-epinephrine, L-norepinephrine (Levophed, Winthrop Lab.), and DL-isoproterenol (Isuprel, Winthrop Lab.) were diluted in a $0.9 \% \mathrm{NaCl}-0.1 \% \mathrm{NaHSO}_{3}$ solution to obtain the proper concentration for injection. The time-response curves were determined after subcutaneous injection of the catecholamine $(500 \mu \mathrm{g} / \mathrm{kg})$. The intravenous infusion of L-epinephrine $\left(0.25 \mu \mathrm{g} / \mathrm{kg} \cdot \mathrm{min}^{-1}\right.$ for $\left.10 \mathrm{~min}\right)$ was accomplished as described previously."

The tissues were excised rapidly from anesthetized animals and frozen in beakers of isopentane cooled in alcohol-dry ice. The liver was excised before the skeletal muscle in all experiments. Phosphorylase and glycogen were assayed as previously reported." The liver sample was diluted such that an equivalent of $5 \mathrm{mg}$ wet weight of liver (1:200 dilution) was assayed. The incubation time for the liver assay was $15 \mathrm{~min}$. All liver phosphorylase determinations were carried out in the presence of $1 \mathrm{mM}$ adenosine monophosphate. The data are expressed as micromoles inorganic phosphate liberated per gram wet weight of liver minute $^{-1}$ incubation time. The skeletal muscle phosphorylase was assayed both with and without the addition of $1 \mathrm{mM}$ adenosine monophosphate and the data are expressed as per cent phosphorylase $a . "$

Blood ghucose was determined by the method of Nelson. ${ }^{10}$ Blood was obtained from a tail vein by means of a Unopette* (generously supplied by Dr. Horace W. Gerarde, Esso Research Lab. and Mr. J. Lucker, Becton, Dickinson and Co.). This allowed the accurate sampling of $13 \mu \mathrm{l}$ of blood which was then diluted and deproteinized. Bloot glucose is expressed as a per cent increase over the daily control level. Over-all mean blood glucose control levels were $92 \cdot 7 \div 3.7 \mathrm{~g} / 100 \mathrm{ml}$ (mean $=$ standard error. $N: \approx 27$ ).

Dichloroisoproterenol (DCI), obtained from the Aldrich Chemical Co., and nethalide (ICI-38, 174), generously supplied by Dr. J. W. Black, were injected subcutaneously $30 \mathrm{~min}$ before catecholamine administration. Ergotamine tartrate (Gynergen, Sandoz) was injected subcutaneously $(1.25 \mathrm{mg} / \mathrm{kg}) 30 \mathrm{~min}$ before catecholamine infusion. Phenoxybenzamine (Dibenzyline, Smith Kline \& French Labs.) was injected intraperitoneally $(5 \mathrm{mg} / \mathrm{kg}$ and $20 \mathrm{mg} / \mathrm{kg}) 2$ to $3 \mathrm{hr}$ before catecholamine administration. Hexamethonium chloride (10 $\mathrm{mg} / \mathrm{kg}$ intraperitoneally) was administered $30 \mathrm{~min}$ before catecholamine infusion.

\section{RESULTS}

The influence of sacrifice under anesthesia and/or decapitation on control lirer phosphorylase levels

Sacrifice by decapitation markedly activated liver phosphorylase (Table 1 ) even if the animal was previously anesthetized. For this reason decapitation was avoided, and tissue samples were obtained under surgical anesthesia.

\section{Lirer phosphorylase and blood glucose levels after catecholamine administration}

Table 2 gives the liver phosphorylase and blood glucose responses after subcutaneous L-epinephrine, L-norepinephrine, and DL-isoproterenol administration. L-Epinephrine injection caused an activation of liver phosphorylase which was maximal at $10 \mathrm{~min}$ after injection. In contrast to the phosphorylase response, the blood glucose levels

\footnotetext{
* Disposable blood-diluting pipet (Becton, Dickinson and Co., Rutherford, N. J.).
} 
after epinephrine administration showed a steady rise throughout the sampling period. Blood glucose determinations at $60 \mathrm{~min}$ after epinephrine injection were somewhat higher than those found at $30 \mathrm{~min}$ (unpublished observations). L-Norepinephrine injection produced liver phosphorylase activation similar to that observed after epinephrine administration; however the blood glucose elevation was neither so rapid

TABLE 1. LiVER PHOSPHORYLASE VALUES AFTER DECAPITATION AND/OR ANESTHESIA

\begin{tabular}{clcc}
\hline $\begin{array}{c}\text { Group } \\
\text { no. }\end{array}$ & Treatment & $\mathrm{N}^{*}$ & $\begin{array}{c}\text { Phosphorylase, } \\
\mu \text { moles } \mathrm{P}_{i} / \mathrm{g} \cdot \mathrm{min}^{-1}\end{array}$ S.E. \\
\hline 1 & $\begin{array}{l}\text { Hexobarbital } \\
(180 \mathrm{mg} / \mathrm{kg}, 10 \mathrm{~min})\end{array}$ & 6 & $4 \cdot 5: 0.9$ \\
2 & $\begin{array}{l}\text { Hexobarbital } \\
+ \text { decapitation } \\
\text { Decapitation }\end{array}$ & 5 & $10 \cdot 1+1.6 \dagger$ \\
3 & 6 & $11 \cdot 8 \pm 1 \cdot 1+$ \\
\hline
\end{tabular}

\footnotetext{
* $N$, number of animals per treatment.

$\dagger 1$ vs. $2 ; P<0.01$.

$\$ 1$ vs. $3 ; \mathrm{P}<0.01$.
}

TABLE 2. TIME-RESPONSE RELATIONSHIPS OF LIVER PHOSPHORYLASE AND BLOOD GLUCOSE LEVELS AFTER SUBCUTANEOUS CATECHOLAMINE*

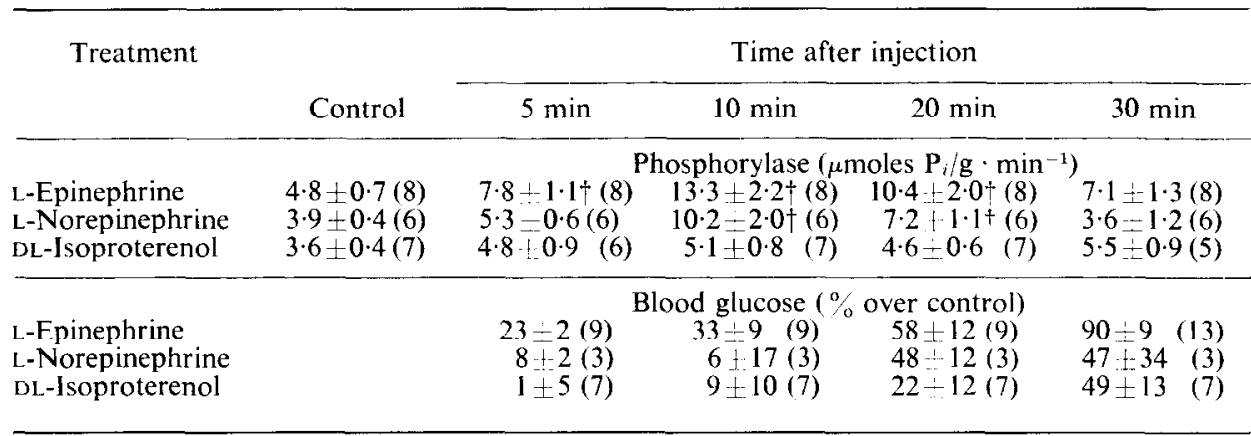

* All catecholamines given subcutaneously $(500 \mu \mathrm{g} / \mathrm{kg}$ ).

Values are means \pm S.E. Numbers of animals per treatment are in parentheses.

$\uparrow$ Significantly different from control $(\mathrm{P}<\mathbf{0 . 0 5})$.

nor so marked as that observed after epinephrine injection. DL-Isoproterenol elicited no statistically significant increase in liver phosphorylase levels at all times measured. and only the 30-min blood glucose sample was significantly higher than control levels,

The influence of adrenergic hlockade on liver and skeletal muscle phosphorylase activation by atecholamines

The data in Table 3 show that L-epinephrine infusion, $0 \cdot 25 \mu \mathrm{g} / \mathrm{kg} \cdot \mathrm{min}^{-1}$ intravenously, for 10 min, elicited an increase in active phosploorylase levels in both liver and skeletal muscle. No significant decrease in glycogen was observed with this dose and time of catecholamine treatment. (Skeletal muscle: control $4.71 \pm 0.28 \mathrm{mg} / \mathrm{g}, \mathrm{N}=8$; epinephrine $4.15 \pm 0.35 \mathrm{mg} / \mathrm{g}, \mathrm{N}=12$. Liver: control $49.2 \pm 1.9 \mathrm{mg} / \mathrm{g}$; epinephrine $43 \cdot 6 \pm 4 \cdot 8$. All, mean \pm standard error.) 


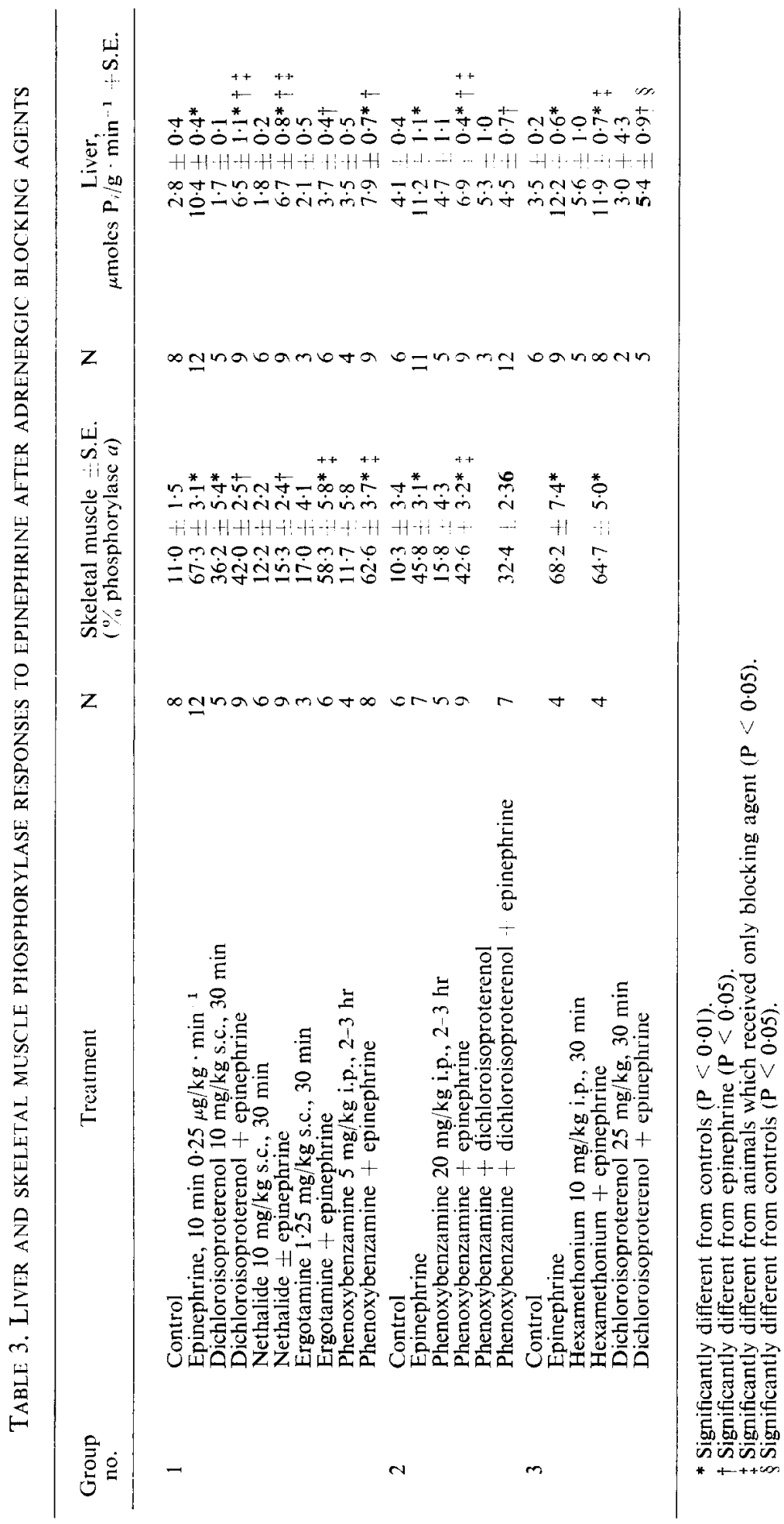


Dichloroisoproterenol (10 or $25 \mathrm{mg} / \mathrm{kg}$ ) caused a moderate activation of skeletal muscle phosphorylase and decreased the epinephrine-induced activation of skeletal muscle phosphorylase to the level of DCI treatment alone (Table 3). DCI treatment produced no activation of liver phosphorylase with the dose of either 10 or 25 $\mathrm{mg} / \mathrm{kg}$. At both $\mathrm{DCl}$ dose levels, partial to complete blockade of the liver response to epinephrine infusion was observed.

Treatment with nethalide (ICI-38, 174), a $\beta$-adrenergic blocking agent with no demonstrable sympathomimetic action, ${ }^{11}$ produced a complete blockade of the epinephrine-induced phosphorylase activation in skeletal muscle and a partial inhibition of the epinephrine effect on liver phosphorylase.

Ergotamine did not significantly affect the skeletal muscle phosphorylase response to epinephrine but did effectively prevent the liver phosphorylase response to epinephrine infusion.

Phenoxybenzamine treatment ( 5 or $20 \mathrm{mg} / \mathrm{kg}$ ) did not influence the skeletal muscle phosphorylase response to epinephrine but partially reduced the increase in liver phosphorylase produced by epinephrine. In contrast to DCI and nethalide, only a moderate blockade of the epinephrine response was observed in all animals at both dose levels of phenoxybenzamine.

Treatment of the animal with both phenoxybenzamine and DCI prior to epinephrine infusion produced more blockade of the epinephrine-induced liver phosphorylase response than that observed after phenoxybenzamine treatment but was not significantly different from the blockade observed after DCI treatment. The skeletal muscle phosphorylase response to epinephrine after the combination blockade was not significantly different from that obtained with DCI treatment alone.

Prior treatment of the rat with hexamethonium $(10 \mathrm{mg} / \mathrm{kg})$ produced no significant change in either the skeletal muscle or liver phosphorylase response to epinephrine infusion.

The skeletal muscle phosphorylase response to epinephrine in the second group of Table 3 is somewhat lower than the epinephrine responses observed in the other two groups, whereas the liver phosphorylase responses to epinephrine in all groups are similar. An explanation for this difference is not apparent.

\section{DISCUSSION}

The mechanism of the catecholamine-induced activation of glycogen phosphorylase has been extensively investigated by Sutherland and his co-workers. In recent reports they have indicated that the catecholamine effect is an indirect one mediated through an accumulation of cyclic $3^{\prime}, 5^{\prime}$ adenosine monophosphate, which then stimulates the formation of active phosphorylase kinase. This enzyme catalyses the conversion of inactive to active phosphorylase.,12-14 The applicability of this system to liver and skeletal muscle has been demonstrated. ${ }^{13,15}$

The activation of liver phosphorylase by the catecholamines has been demonstrated conclusively in the liver slice of several species. ${ }^{3,16,17}$ Liver phosphorylase activation after catecholamine administration in vivo has been observed in the rabbit ${ }^{3}$ but not in the rat. ${ }^{4,5,18}$ The present data indicate that, with an adequate dose of catecholamine, rat liver phosphorylase activation can be obtained in vivo. Although the dose of catecholamine was larger than that used by other investigators, the method of sacrifice B.P. $-3 \mathrm{U}$ 
of the animal and the time of sampling appear to be as important as the dose of catecholamine employed to demonstrate liver phosphorylase activation.

In the investigations mentioned above in which no liver phosphorylase activation was observed after epinephrine administration, the control phosphorylase levels reported were in the range of 9 to $10 \mu \mathrm{M}$ inorganic phospliate/g.min 1, 1, 5, 1*. This is somewhat higher than the control values $\left(2 \cdot 8\right.$ to $4.9 \mu \mathrm{M}$ inorganic phosphate $\left./ \mathrm{g} \cdot \mathrm{min}^{-1}\right)$ reported in the present investigation and may be sufficiently high so that an epinephrine-induced activation would be masked. Also, in the investigations in which phosphorylase activation could not be demonstrated after epinephrine administration, tissue samples were not usually taken before $30 \mathrm{~min}$ after epinephrine injection. As may be seen in Table 2, at this time a considerable portion of the catecholamineinduced phosphorylase activation was dissipated.

The problem of what constitutes a "ieasonable" control phosphorylase value for liver has not been extensively discussed. It has been generally found that liver slices have lower phosphorylase levels than those values obtained after tissue sampling in rico. An exact level of active liver phosphorylase as a percentage of the total enzyme present is difficult to determine because inactive liver phosphorylase is not stimulated to activity by the addition of adenosine monophosphate. ${ }^{16}$ From our data with epinephrine stimulation of rat liver phosphorylase, it appears that the total liver phosphorylase activity is in the range of 15 to $20 \mu \mathrm{M}$ inorganic phosphate $/ \mathrm{g} \cdot \mathrm{min}^{-1}$ assayed at 30 . If it is further assumed that the active liver phosphorylase is present in cito in the same relationship to total enzyme content as occurs in heart and skeletal muscle ( 0 to $12 \%$ active phosphorylase), ${ }^{15,19,20}$ then the control liver phosphorylase levels in vivo would be approximately 0.0 to $2.4 \mu \mathrm{M}$ inorganic phosphate $/ \mathrm{g} \cdot \mathrm{min}^{-1}$. Our control values for liver phosphorylase in vivo approach this range. Cornblath ${ }^{16}$ has reported liver phosphorylase values of this magnitude for rabbit liver slices in vitro. Other investigators using both in-ritro ${ }^{17}$ and in-rivo sampling ${ }^{4,5,18}$ have reported higher control phosphorylase levels for rat liver. A possible explanation for some of these differences in control phosphorylase levels may be that a conversion of inactive phosphorylase to active phosphorylase occurs after excision of the liver even though the tissue is maintained at $0^{\circ}$. A similar conversion of inactive to active phosphorylase during homogenization has been reported for skeletal muscle ${ }^{19}$ and heart ${ }^{6}$ samples.

The relative potencies of the catecholamines for rat liver phosphorylase activation in vivo appear to be L-epinephrine > L-norepinephrine $>$ oL-isoproterenol. This order of potency has also been observed for the hyperglycemic response to catecholamines in the intact rat ${ }^{21}$ and glucose production by rat liver slices. ${ }^{22}$ A different order of potency for glycogen mobilization has been previously determined for $\operatorname{rat}$ heart ${ }^{9}(1>E \ldots N E)$ and rat skeletal muscle ${ }^{23}(\mathrm{E}>\mathrm{I}>\mathrm{NE})$. Mayer et al. ${ }^{6}$ determined that catecholamine potency ratios for hyperglycemia in the intact $\operatorname{dog}$ are $I=E>N E$. A similar order of catecholamine potency was reported by Sutherland and Rall ${ }^{1}$ for phosphorylase activation in dog liver homogenate and by Murad et al. ${ }^{13}$ for cyclic $3^{\prime}, 5^{\prime}$-adenosine monophosphate production in the washed particulate fraction of dog liver. It would therefore appear, on the basis of sensitivity of the liver phosporylase activation to catecholamines, that a considerable species difference exists between the adrenergic receptor of the rat and dog liver. The insensitivity of rat liver phosphorylase to isoproterenol administration is further demonstrated by the fact that the dose used in this 
investigation is ten times higher than that necessary to produce a marked activation of heart and skeletal muscle phosphorylase. ${ }^{9}$

The time course of the liver phosphorylase activation after subcutaneous catecholamine administration is different from that observed in rat heart and skeletal muscle. ${ }^{9}$ In the latter tissues, peak phosphorylase activation occurred at 5 min or earlier after catecholamine injection. In the liver, peak phosphorylase activation did not occur until $10 \mathrm{~min}$ after injection and was decreased $30 \mathrm{~min}$ after injection. In contrast to heart and skeletal muscle phosphorylase, the liver phosphorylase time-response curve did not parallel the plasma epinephrine level which we have previously reported to be maintained at a relatively constant concentration (approximately $9 \mu \mathrm{g} / \mathrm{l}$ ) from 5 to $60 \mathrm{~min}$ after a subcutaneous epinephrine injection of $500 \mu \mathrm{g} / \mathrm{kg} .{ }^{9}$ An explanation for this delayed response in the liver is not apparent. It is possible that catecholamineinduced vascular changes in the liver altered the drug distribution pattern leading to a gradual rise in the concentration of the catecholamine at the receptor site.

The relationship of the blood glucose changes to the alteration in liver phosphorylase after catecholamine administration suggest that a change in blood glucose is not indicative of the degree or duration of a liver phosphorylase response. In fact, the blood glucose level after epinephrine injection was still increasing at $1 \mathrm{hr}$ after epinephrine, even though the phosphorylase activity had declined somewhat at $30 \mathrm{~min}$. In addition, the blood glucose responses to norepinephrine and isoproterenol did not mirror the responses of liver phosphorylase. Cahill et al. ${ }^{21}$ have reported a similar lack of correlation between liver phosphorylase activation and blood glucose changes after glucagon infusion in the dog.

The classification of the liver phosphorylase response to epinephrine as either an $\alpha$ or $\beta$ - or both an $\alpha$ - and $\beta$-adrenergic receptor appears to be somewhat difficult. The inability of phenoxybenzamine to cause more than a partial reduction in the epinephrine-induced increase in liver phosphorylase, whereas ergotamine completely abolished the response, suggests that the usual $a$-adrenergic receptor is not involved in the epinephrine action. Harvey et al $^{25}$ reached a similar conclusion based upon the dissociation between the relative abilities of phenoxybenzamine and ergotamine to block the vasoconstrictor response and the hyperglycemia observed after epinephrine administration.

In addition, the liver phosphorylase response was reduced by the $\beta$-adrenergic blocking agents, DCI and nethalide. Both of these compounds caused a partial, and in several animals a complete, blockade of the rat liver phosphorylase response to epinephrine. Treatment with both $\alpha$ - and $\beta$-receptor blocking agents did not aid in defining the nature of the liver adrenergic receptor. Although the catecholamine potency ratio for rat liver phosphorylase activation in vivo $(\mathrm{E}>\mathrm{NE}>\mathrm{I})$ fits that order postulated by Furchgott ${ }^{26}$ necessary to define an $\alpha$-adrenergic receptor, we do not feel that a definite classification can be determined at this time.

The experiments with hexamethonium treatment demonstrate that depression of the automatic nervous system, at a site other than the postganglionic adrenergic receptor, does not alter the epinephrine-induced liver phosphorylase activation.

The phorphorylase data presented above for the interaction of adrenergic blocking agents with epinephrine is in general agreement with the data of Kennedy and Ellis, ${ }^{27}$ who measured tissue glycogen levels after epinephrine administration and $a$ - and $\beta$-adrenergic blocking agents. 
The skeletal muscle receptor for phosphorylase activation by catecholamines appears to be classified as a $\beta$-adrenergic receptor both with respect to relative potencies of the catecholamines and the comparative ability of the various adrenergic blocking agents to block the epinephrine response. The blockade of skeletal muscle phosphorylase activation produced by DCI and methalide is dependent on the dose of catecholamine employed. The phosphorylase activation produced by the subcutaneous injection of $50 \mathrm{mg}$ of isoproterenol $/ \mathrm{kg}$ was not blocked in skeletal muscle by $5 \mathrm{mg}$ of $\mathrm{DCI} / \mathrm{kg}$, whereas in the same animal the isoproterenol-induced cardiac phosphorylase activation was abolished (unpublished observations). This dependence of DCI blockade in skeletal muscle on the test dose of catecholamine employed may help explain why it has been difficult to demonstrate consistent blockade of catecholamineinduced lactic acidemia. ${ }^{6}$

The dosage and time schedule of epinephrine infusion used in this investigation did not cause a significant reduction in the glycogen level of either liver or skeletal muscle. We have previously observed decreased glycogen levels in skeletal muscle at this time after epinephrine administration, using a different dose and route of administration."

It is possible to estimate the glycogen mobilization from the published values for phosphorylase activites in liver and skeletal muscle (assayed in the direction of glycogen breakdown). ${ }^{28}$ In liver, phosphorylase activity of $5 \mu$ moles $/ \mathrm{g} \cdot \mathrm{min}^{-1}$ (which corresponds to a phosphorylase activity of approximately 10 to $15 \mu \mathrm{moles} / \mathrm{g} \cdot \mathrm{min}^{-1}$ assayed in the direction of glycogen synthesis) would mobilize $9 \mathrm{mg}$ glycogen $/ \mathrm{g}$ wet weight liver in $10 \mathrm{~min}$. This glycogen loss would be difficult to detect in fed rats and may explain why significant glycogen loss is more easily detected in fasted rats which have lower initial glycogen levels. In skeletal muscle, however, the level of phosphorylase activity after epinephrine administration (assuming 65\% activation) is $18 \mu$ moles $\mathrm{g} \cdot \mathrm{min}^{-1}$. This should mobilize glycogen at the rate of $3.6 \mathrm{mg}$ glycogen $/ \mathrm{g}$ wet weight $\cdot \mathrm{min}^{-1}$. That this rate of glycogen loss is not approached, in this or a previous report on catecholamine-induced skeletal muscle glycogenolysis, ${ }^{9}$ further emphasizes that factors other than the level of tissue phosphorylase activation control the degree and rate of glycogen loss in skeletal muscle.

One possibility is that glycogen synthesis by the uridinediphosphoglucose-transglycolase pathway is sufficient to compensate for the glycogen loss. However, the maximal tissue levels of skeletal muscle glycogen synthetase activity (assayed in the presence of glucose-6-phosphate, $2 \cdot 0 \mu$ moles $\left./ g \cdot \mathrm{min}^{-1}\right)^{29,30}$ would appear to be considerably lower than those necessary to compensate for glycogen breakdown by phosphorylase activation.

The importance of factors other than the level of tissue phosphorylase in regulating glycogen metabolism has been noted recently by us $^{9}$ and by others. ${ }^{31-3 t}$

Acknowledgments - The authors wish to acknowledge the excellent technical assistance of Miss Carol Lengler and Mr. Gerald Grumet in this research.

\section{REFERENCES}

1. E. W. Sutherland and T. W. Rall, Pharmacol. Rev. 12, 265 (1960).

2. S. Ellis, Pharmacol. Rev. 8, 485 (1956).

3. E. W. Sutherland and C. F. Cort, J. biol. Chem. 188, 531 (1951).

4. H. Niemeyer, C. Gonzalez and R. Rozzi, J. biol. Chem. 236, 610 (1961).

5. W. F. Perske, D. C. KVam and R. E. Parks, JR., Biochem. Pharmacol. 1, 141 (1958). 
6. S. E. Mayer, N. C. Moran and J. FaIn, J. Pharmacol. exp. Ther. 134, 18 (1961).

7. E. W. Sutherland, Phosphorus Metabolism, W. D. McElroy and B. Glass, Eds., vol. 2. Johns Hopkins Press Baltimore (1952).

8. G. T. CORI and B. Illingworth, Biochim. biophys. Acta 21, 105 (1956).

9. K. R. HornBrook and T. M. Brody, J. Pharmacol. exp. Ther. 140, 295 (1963).

10. N. Nelson, J. Biol. Chem. 153, 375 (1944).

11. J. W. BLACK and J. S. Stephenson, Lancet 2, 311 (1962).

12. E. E. Sutherland, T. W. Rall and T. Menon, J. biol. Chem. 237, 1220 (1962).

13. F. Murad, Y.-M. Chi, T. W. Rall and E. W. Sutherland, J. biol. Chem. 237, 1233 (1962).

14. L. M. Klainer, Y.-M. Chi, S. L. Freidberg, T. W. Ralll and E. W. Sutherland, J. biol. Chem. 237, 1239 (1962).

15. J. B. Posner, R. Stern and E. G. Krebs, Biochem. biophys. Res. Commun. 9, 293 (1962).

16. M. Cornblath, Amer. J. Physiol. 183, 240 (1955).

17. T. W. Rall, E. W. Sutherland and W. D. Wosilait, J. biol. Chem. 218, 483 (1956).

18. K. H. SHULL, J. biol. Chem. 237, PC 1734 (1962).

19. W. H. Danforth, E. Helmrich and C. F. Cori, Proc. nat. Acad. Sci. (Wash.) 48, 1191 (1962).

20. S. E. Mayer, M. DeV. CotTen and N. C. Moran, J. Pharmacol. exp. Ther. 139, 275 (1963).

21. S. Ellis and H. L. ANDerson JR., J. Pharmacol. exp. Ther. 101, 92 (1951).

22. F. P. VAN RuY and L. W. SChulof, Arch. int. Pharmacodyn. 130, 368 (1961).

23. C. VRIJ, B. K. GHo, C. A. De GroAt and J. F. WeBer, Acta physiol. pharmacol. neerl. 4, 547, (1956).

24. J. F. CAHILL, S. ZotTu and A. S. EARLE, Endocrinology 60, 265 (1957).

25. S. C. Harvey, C.-Y. WANG and M. Nickerson, J. Pharmacol. exp. Ther. 104, 363 (1952).

26. R. F. FURCHGOTT, Pharmacol. Rev. 11, 429 (1959).

27. B. L. Kennedy and S. Ellis, Fed. Proc. 22, 449 (1963).

28. C. Villar-Palasi and J. Larner, Arch. Biochem. 86, 270 (1960).

29. C. Villar-Palasi and J. Larner, Arch Biochem. 94, 436 (1961).

30. M. Rosell-Perez, C. Villar-Palasi and J. LARNer, Biochemistry 1, 763 (1962).

31. B. M. Breckenridge and J. H. Norman, J. Neurochem. 9, 383 (1962).

32. J. B. LYON and J. PORTER, J. biol. Chem. 238, 1 (1963).

33. S. E. MAYer, Biochem. Pharmacol. 12, 193 (1963).

34. A. Parmeggiani and H. E. Morgan, Biochem. biophys. Res. Commun. 9, 252 (1962). 